\title{
Vicdan Algısı Ölçeği’ nin Hemşirelerde Türkçe Geçerlilik Güvenilirliği
}

\author{
Sena Dilek Aksoy ${ }^{1 *}$, Kader Mert ${ }^{2}$, İbrahim Çetin ${ }^{3}$ \\ ${ }^{11}$ Kocaeli Üniversitesi Sağlık Bilimleri Fakültesi Ebelik Bölümü, Kocaeli, Türkiye \\ ${ }^{2}$ İzmir Bakırçay Üniversitesi Sağlık Bilimleri Fakültesi Hemşirelik Bölümü, İzmir, Türkiye \\ ${ }^{3}$ Kocaeli Üniversitesi Sağlık Bilimleri Fakültesi Hemşirelik Bölümü, Kocaeli
}

email: senadilek2010@gmail.com, kadermert@gmail.com, cetinibrahim1@ hotmail.com

Orcid: 0000-0003-4366-5056

Orcid: 0000-0002-5035-7230

Orcid: 0000-0002-2340-6201

*Sorumlu Yazar / Corresponding Author: Sorumlu Yazar: Sena Dilek Aksoy

Gönderim Tarihi / Received: 01.08.2019

Kabul Tarihi / Accepted: 25.09.2019

DOI: $10.34087 /$ cbusbed.599744

\begin{abstract}
Amaç: Zihinsel bir süreç olan vicdan, özel ve mesleki yaşamda tutum ve davranışlara etki eden, felsefi, etik ve ahlaki yönü bulunan çok boyutlu bir kavramdır. Hemșirelerin çalıșma hayatlarında hissettikleri vicdani rahatsızlık, ilerleyen süreçte suçluluk, hüzün, umutsuzluk ve güçsüzlük gibi olumsuz duygular yaşamalarına ve mesleki tükenmişliklerine sebep olabilir.

Yöntem: Bu araştırma metodolojik bir araştırma olup, 163 hemşire ile yapılmıştır. Verilerin toplanmasında tanıtıcı bilgi formu ve Dahlqvist ve arkadaşları tarafından geliştirilen vicdan algısı ölçeği kullanılmıștır. Ölçeğin dil uyarlaması ve içerik geçerlilik incelemesinin değerlendirilmesinin ardından veriler, kapsam geçerlilik için uzmanlar arası uyum bakımından değerlendirilmiştir. Yapı geçerliliği için ise faktör analizi yapılmıştır. Güvenilirlik çalışması, madde toplam korelasyonu, Cronbach alfa katsayıları ve test tekrar test ile incelenmiștir.

Bulgular: Ölçeğin kapsam geçerliliği değerlendirme puanları bakımından uzman görüșleri arasında uyum saptanmıştır (Kendall's W=0,114; $\mathrm{p}=0,101>0,05$ ). Ölçeğin madde-toplam puan korelasyon katsayıları (r) 0,090 0,697 arasında olduğu ve aralarındaki ilişkinin pozitif yönde istatistiksel yönden ileri düzeyde anlamlı olduğu (p < $0,001)$ bulunmuştur. Güvenirlik analizlerinde Cronbach Alpha katsayısı 0,84 ve test tekrar test korelasyon katsayısı $\mathrm{r}=0,97$ 'dir.
\end{abstract}

Sonuç: İstatistiksel değerlendirmede, 16 maddeli ölçeğin 3 maddesinin ölçekten çıartılarak, 13 maddeli haliyle Türkiye'deki hemşirelerle ilgili yapılacak çalışmalarda kullanılması uygun bulunmuştur.

Anahtar Kelimeler: Hemșirelik, Vicdan, Algı.

\footnotetext{
Abstract

Objective: Conscience is a mental process that affects attitudes and behaviors in private and professional life and a multidimensional concept with philosophical, ethical and moral aspects. The conscientious disturbance experienced by nurses in professional life may lead to negative feelings such as guilt, sadness, hopelessness and weakness, and may cause them to experience professional burnout in the future.

Method: This study is a methodological research, and the study consisted of 163 nurses. Data were collected using a personal information form and the Perceptions of Conscience Questionnaire developed by Dahlqvist et al. After the assessment of the language adaptation and content validity of the scale, data were analyzed in terms of inter-rater agreement for content validity. Factor analysis was used for construct validity. The reliability of the instrument was evaluated using item total correlation, Cronbach's alpha coefficients and test-retest analyzes.

Results: There was an inter-rater agreement in terms of the content validity evaluation scores of the questionnaire (Kendall's W=0.114; $\mathrm{p}=0.101>0.05$ ). The item-total score correlation coefficients $(\mathrm{r})$ of the scale were between 0.090 and 0.697 , and there was a positively significant relationship between them $(p<0.001)$. In the reliability analysis, Cronbach's alpha coefficient was 0.84 and test-retest correlation analysis $r=0.97$ was determined.

Conclusion: The statistical data showed that, after removing three items from the original version of the 16-item questionnaire, the 13-item Turkish version of the questionnaire is suitable for use in studies to be conducted with nurses in Turkey.

Keywords: Nursing, Conscience, Perception.
} 


\section{Giriș}

Zihinsel bir süreç olan vicdan, özel ve mesleki yaşamımızda tutum ve davranışlarımıza etki eden, felsefi, etik ve ahlaki yönü bulunan çok boyutlu bir kavramdır. Vicdan, bu etkisini bizim için içsel bir rehber olarak gösterir, ne yapmamız gerektiğini hatırlatır, ahlaki ve etik bir farkındalık oluşturur [1]. Vicdan kelimesinin kökeni Latinceden gelmektedir. "Conscientia" kelime anlamı olarak: bir insanın doğru ve yanlış ile ilgili, davranışlarına rehberlik eden ahlak anlayışı olarak tanımlanmaktadır [2]. İnsanoğlu çok eski zamanlardan beri vicdanı açıklama ve pratiğe yansımasını ele alma gibi yararlı bir çaba içinde olmuştur. Vicdanın kavramsal olarak ortaya çıkışı eski Yunan'a, Aristoteales'e kadar uzanmaktadır [3]. Aristotales'in Aristoteles'in felsefi öğretilerinden etkilenen, Ortaçağ felsefesinin önemli düşünürlerinden biri olan Aquinas, insanoğlunun süregelen iyilik ve erdemlerini açıklamaya yönelik bir vicdan teorisyeni olarak kabul edilir. D'Arcy, Aquinas'in öğretisini referans alarak vicdanı; geçmişteki davranışları ve gelecekteki davranışları dikkate alan vicdan olarak ikiye ayırır. Aquinas'a göre; insanlar geçmişteki davranış ve tercihlerini, yarg1 süzgecinden geçirerek gelecekteki davranışlarını şekillendirir [4]. Özü itibariyle akıl, duygular ve kişisel bütünlüğe odaklanan vicdan, kişisel değerler kadar kültürel ve sosyal koşullardan da etkilenen bir iç sestir [5,6].

Doğrudan insana hizmet sunan ve çoğu zaman kolay incinebilir ve hassas topluluklarla çalışan sağlık ekibi üyeleri için vicdan önemli bir kavramdır. Sağlık çalışanları hastalardan, onların yakınlarından ve kendi iş arkadaşlarından gelen istekleri ve ortaya çıkan gereksinimleri dengelemek zorundadır. $\mathrm{Bu}$ faktörler dengelenemediğinde hastayla ilgili uygulamalar konusunda vicdani çelişkiler ya da çatışmalar yaşanabilir [7]. Ayrıca yaşanan vicdani sorunlar hastanın aldığı hizmeti ve sağlığını olumsuz etkileyebilir [8]. Dahası, Sağlık çalışanını benimsediği değerlerin ihlaline karşı uyararak kişisel bütünlüğünü korumasına yardım eden vicdan, yaşanan çatışmalar ve ikilemler nedeniyle tükenmişliğe yol açabilir. Kişisel ve mesleki değerlerimize, inançlarımıza ve etik ilkelere uygun olmayan durumlarla karşılaştığımızda vicdanımız bizi uyarır. $\mathrm{Bu}$ uyarı, onu görmezden gelene ya da durumla ilgilenene kadar devam eder [9]. Vicdanın sesine kulaklarını tıkama ya da karşılaşılan olumsuz durum için çözüm üretmede yetersiz kalma kişise bütünlük için olduğu kadar fizyolojik, psikolojik, sosyal ve çalışma ortamı sağlığı için de bir tehdit kaynağıdır $[8,10,11]$.

Hemşirelik etik açıdan karmaşık bir meslektir.

Vicdan, hemşirelik bakımını olumlu yönde etkileyen ve daha ileriye taşıyan etik bir kavramdır. Hemşirelikte vicdan, bir otorite, bir uyarı sinyali, zahmetli bir hassasiyet, değerli bir şey ve aynı zamanda yük olarak algilanabilmektedir [3]. Hemşireler görevini yerine getirirken vicdani bir rahatsızlı duyduklarında suçluluk, hüzün, umutsuzluk ve güçsüzlük gibi olumsuz duygular yaşayabilir. Bu duygular vicdan azabının sonucudur. Vicdan azab1 "insana acı veren bir vicdanı" temsil eder. Yaşanılan duygular çalışma ortamının dışına, özel hayata taşınabilir. Algılanan vicdani sorun çözülmezse çalışma ortamı olumsuz etkilenir. Bu durum hemşireyi sağllk sisteminde çalışmaya devam edebilmek için vicdanını göz ardı etmeye zorlayabilir. Dahası, hemşirede tükenmişliğe neden olur [5,9]. Ülkemizde vicdan algısını ölçmek için kullanılan geçerli ve güvenilir bir ölçüm aracı bulunmamaktadır.

Çalışma 2007 yılında Dahlqvist ve arkadaşları tarafından geliştirilen vicdan algısı ölçeğinin Türkiye'de hemşirelerin vicdan algısını belirlemede ölçme aracı olarak kullanılabilirliğini test etmek için yapılmıştır.

\section{Gereç ve Yöntem}

\subsection{Araștırmanın Amacı}

$\mathrm{Bu}$ araştırma, hemşirelerin vicdan algısını değerlendirmek üzere geliştirilen "Vicdan Algısı Ölçeğì"nin Türkiye'de geçerlilik ve güvenilirliğini test etmek ve faktör yapısını incelemek amacıyla yapıldı.

\subsection{Araştırmanın Tipi}

Bu çalışma, metodolojik bir araştırmadır.

\subsection{Araştırmanın Yeri ve Zaman}

Araştırma bir üniversite hastanesinde Ocak - Mart 2018 tarihleri arasında yapıldı.

\subsection{Evren ve Örneklem}

Ölçek geçerlilik ve güvenilirlik çalışmalarında faktör analizi uygulayabilmek için örneklemin ölçek madde sayısının en az 5-10 katı olması önerilmektedir. Testtekrar test değerlendirmesinin yapılabilmesi için de en az 30 çift veri olması gerektiği bildirilmektedir [12].

Çalışma evrenini 270 hemşire oluşturmuş olup, hem test-tekrar test analizi hem de geçerlilik ve diğer güvenilirlik testleri açısından uygunluğu sağlamak için 163 hemşire araştırmaya katılmıştır. Araştırmada örnekleme tekniği kullanılmamış, araştırma evrenin tümüne ulaşılmaya çalışılmış fakat çalışma evrenin \%60'ına ulaşılmıştır.

\subsection{Veri Toplama Araçlar}

Araştırmanın verileri "Hemşire Tanıtım Formu" ve 16 maddeden oluşan "Vicdan Algısı Ölçeği” ile toplandı.

Hemşire Tanıtım Formu; kişisel özelliklerin (yaşı, cinsiyeti, meslek seçimi) yer aldığ 1 form olup, Testtekrar test yaptırırken "rumuz" ya da "takma isim" kullanarak veriler topland1.

\section{Vicdan Algısı Ölçeği (Perception of Conscience} Questionare)

Dahlqvist ve arkadaşları tarafından 2007 yılında geliştirilen ölçeğin orjinali 15 maddeden oluşmakta, ölçüm değeri için 6'lı likert kullanılmaktadır. Ölçeğin değerlendirmesinde "Hayır, Tamamen katılmiyorum" (1 puan); "Evet, tamamen katılıyorum" (6 puan) olarak puanlandırılmaktadır. Ölçek, altı alt ölçekten oluşmaktadır: Otorite (Auhority) (Madde 6,10,14,15), Uyarı işaretleri (Warning Signal) (Madde 3,4,5), Adanmış duyarlılık (Demanding Sensitivity) (Madde 1,2,10), Değer (Asset) (Madde 7,8), Yük (Burden) 
(Madde 11,12), Kültüre bağlı (Depending Culture) (Madde 9,13). Ölçekten alınan puanın yüksek olması, vicdan algısının yüksek olduğunu göstermektedir [5]. Daha sonra Ahlin ve arkadaşları tarafindan bu ölçeğe bir madde daha eklenmiştir. Bu çalışmada ölçeğin, 16 maddelik son hali kullanılmıştır [6].

\section{6. Ön araştırma}

\section{Psikolinguistik özelliklerin incelenmesi}

Ölçeklerin Türk diline uyarlama çalışması için çevirigeri çeviri (back translation) tekniği kullanıldı. Vicdan Algısı Ölçeği’nin dil geçerliliği için, önce orijinal dili İngilizce olan ölçeğin Türkçe'ye çevirisi dört uzman tarafından yapıldı. Ardından iki dili çok iyi bilen, bir mütercim tercüman tarafindan Türkçe'den İngilizce'ye tekrar çevrisi yapıldı. İngilizce tercüme metni ile orjinal ölçek metni karşılaştırıldı ve Türkçe tercüme metninin son hali oluşturuldu. Ölçek son hali ile hemşirelere uyguland.

\section{Psikometrik özelliklerin incelenmesi}

Ölçeğin uyum geçerliliğinde, maddelerin anlaşılırlık, basitlik ve konuyla ilişkisini belirlemeye yönelik olarak uzman görüşleri alındı ve alanında uzman 13 akademisyen tarafindan değerlendirmesi yapıldı. Geçerlilik çalışmasında içerik/kapsam geçerliliği (uzman görüşü) için Kapsam Geçerliliği İndeksi (CVI) ve değerlendiricilerin verdikleri puanların uyumunu ölçmek amacıyla Kendall Uyuşum Katsayısı (W) hesaplandı. Daha sonra pilot uygulaması yapıldı ve veri toplama aşamasına geçildi. Güvenilirlik çalışmasında ise ölçeklerin ve alt boyutlarının iç tutarlılığı için Cronbach alfa katsayısı, madde toplam puan analizi için Pearson korelasyon analizi yapıldı.

\subsection{Araştırmanın Etik Yönü}

Araştırma öncesi Vera Dahlqvist ve Sture Eriksson'dan internet ortamında ölçeğin Türkçe versiyonunun geçerlilik ve güvenirliğini yapabilmesi konusunda yazılı onay alındı. Yazalar, ölçeği ve aşamaları hakkındaki gerekli verileri e-posta yolu ile iletti. Ayrıca çalışmayla ilgili üniversitenin Araștırma Etik Kurulu'ndan etik onay ve kurum izinleri de alındı. Araştırmanın Etik Kurul Onay kodu XX XXXXXX 2017/370'dir. Veri toplamadan önce hemşirelere çalışma ile ilgili gerekli açıklama yapıldı ve elde edilen verilerin gizli kalacağ konusunda güvence verilip, yazılı ve sözlü onamları alındi.

\subsection{Veri Toplama Araçlarının Uygulanması}

Veriler araştırmacılar tarafından toplandı, gerekli açıklamalar yapıldıktan sonra gönüllü hemşirelerden rumuz kullanarak soru formlarını öz bildirime dayalı olarak doldurmaları istendi.

\subsection{Araştırmanın Sınırlılıkları}

Çalışmanın yapıldığı kurumda çok sayıda araştırmanın kurumda yapılıyor olması, yoğun mesai saati ve vardiyalı çalışma katılımcıların araştırmaya katılma konusunda dirence neden olmuş ve gönüllülük esasına dayalı katılım oranı azalmıştır.

\subsection{Verilerin Değerlendirilmesi}

Araştırma verileri, uygun istatistik paket programı ile bilgisayar ortamında analiz edildi. Katılımcıların tanımlayıcı özellikleri, aritmetik ortalama, standart sapma, minimum, maksimum ve yüzde ile değerlendirildi. Kapsam geçerlilik analizleri için Waltz ve Bausell tarafından geliştirilen Kapsam Geçerlilik Indeksi (CVI) ve Kendall Uyuşum Katsayısı (W) testleri yapıldı. Güvenilirlik değerlendirmelerinde Pearson Korelasyonu ve Cronbach alfa analizleri yapıldı. Faktör analizine geçilmeden önce verilerin yeterli olup olmadığını belirlemek amacıyla Kaiser-Meyer Olkin (KMO) ve Barlett testleri yapıldı ve bu çerçevede faktör analizi kullanıldı. Faktör Analizi (Equamax Rotasyon)'nde ölçeğin 2 faktöre ayrıldığı bulundu. Ölçeğin zamana göre değişmezliği bağımlı gruplarda $t$ testi (Paired samples t test) ve Pearson Momentler Çarpımı Korelasyon Katsayısı ile değerlendirildi.

\section{Bulgular}

Çalışmaya katılanların $\quad(n=163)$ yaş ortalaması 31,16 $\pm 6,29$ (Yaş aralığı 19-55) olup, \%82'si kadın ve \%71,8'inin mesleği isteyerek seçmiştir.

\subsection{Geçerlilik Bulguları}

\section{Kapsam geçerliliği}

Ölçek maddelerinin kapsam geçerliliği (CVI) ve Kendall W kullanılarak hesaplandı; uzmanlardan her bir ölçek maddesinin kapsam ve dil yönünden uygunluğunu 1-4 arasında bir puan ile değerlendirilmeleri istendi (1 puan: "ifade uygun değil", 2 puan: "ifade biraz uygun/ifadenin revizyonu gerekir", 3 puan: "ifade oldukça uygun ancak ufak değişiklik gerekir", 4 puan: "ifade çok uygun"). Her bir uzmanın her bir ifade için verdiği puan dikkate alınarak her bir maddenin uygunluğunu 3 veya 4 olarak bildiren yanıtların yüzde değeri hesaplandi.

Vicdan Algısı Ölçeği kapsam geçerliliği değerlendirme puanları; Kendall's W testi ile analiz edildiğinde; uzman görüşleri arasında istatistiksel olarak fark olmadığ (Kendall's W=0,114; $\mathrm{p}=0,101>0,05$ ) bulunmaktadır.

\subsection{Güvenilirlik Bulguları}

İç tutarlılık ve madde analizlerinde madde-toplam ölçek çözümlemesi ve Cronbach alpha güvenilirlik analizleri yapild1.

Ölçeğin madde-toplam puan korelasyon katsayıları (r) 0,090 - 0,697 arasında olduğu ve aralarındaki ilişkinin pozitif yönde istatistiksel yönden ileri düzeyde anlamlı olduğu $(\mathrm{p}<0,001)$ saptandı. Madde 9, Madde 11 ve Madde 12 madde - toplam korelasyonu 0,20'nin altında olduğu için ölçekten çıkarılması uygun bulundu (Tablo 1). Güvenirlik analizleri kapsamında Cronbach Alpha ve test-tekrar test kullanıldı. Cronbach Alpha katsayısı 0,84 'dür.

3.2.1. Test-tekrar test (Zamana göre değişmezlik) güvenilirliği sonuçları

Ölçeğin test-tekrar test puan ortalamaları arasındaki uyumluluk durumunu belirlemek amaciyla korelasyon analizi (Pearson Momentler Çarpımı Korelasyonu) yapıld 1 ve $r=0,97$ tespit edildi. 
Tablo 1. Vicdan Algısı Ölçeği Madde Korelasyonları $(n=163)$

\begin{tabular}{|c|c|c|c|}
\hline Maddeler & Ortalama $\pm \mathbf{S s}$ & $\begin{array}{l}\text { Item-Total } \\
\text { Correlation }\end{array}$ & $\begin{array}{c}\text { Cronbach's Alpha if } \\
\text { Item Deleted }\end{array}$ \\
\hline $\begin{array}{l}\text { Madde 6- İnsanların ne düşündüklerine bakmaksızın } \\
\text { vicdanımızın sesini dinlemeliyiz. }\end{array}$ & $4.34 \pm 1.42$ & 0.369 & 0.845 \\
\hline \begin{tabular}{|lccc}
$\begin{array}{l}\text { Madde } \\
\text { vicdanımız zayıflar. }\end{array}$ & vicdanımızın & sesini & dinlemezsek. \\
\end{tabular} & $4.04 \pm 1.56$ & 0.373 & 0.846 \\
\hline Madde 14 -Tanrı. vicdanımız vasıtasıyla bizimle konuşur. & $3.84 \pm 1.50$ & 0.524 & 0.837 \\
\hline $\begin{array}{l}\text { Madde 15-Vicdanımı dinlediğimde bir insan olarak } \\
\text { olgunlaşırım. }\end{array}$ & $4.23 \pm 1.31$ & 0.697 & 0.827 \\
\hline Madde 3- Vicdanımızın sesinden kaçamayız. & $4.34 \pm 1.41$ & 0.602 & 0.832 \\
\hline $\begin{array}{l}\text { Madde 4-Vicdanımız. kendimize zarar vermemize engel } \\
\text { olur. }\end{array}$ & $3.73 \pm 1.46$ & 0.543 & 0.835 \\
\hline $\begin{array}{l}\text { Madde 5-Vicdanımız başkalarına zarar vermeye karşı bizi } \\
\text { uyarır. }\end{array}$ & $4.65 \pm 1.19$ & 0.666 & 0.830 \\
\hline Madde 1 -Vicdanın sesi dinlenmelidir. & $4.61 \pm 1.08$ & 0.639 & 0.833 \\
\hline Madde 2- Vicdanın sesini duyabilmek için iç huzur gerekir. & $4.09 \pm 1.37$ & 0.599 & 0.832 \\
\hline $\begin{array}{l}\text { Madde7- Çalışma hayatımda vicdanım ne söylüyorsa onu } \\
\text { ifade edebilirim. }\end{array}$ & $4.12 \pm 1.21$ & 0.548 & 0.836 \\
\hline Madde 8- Çalışma hayatımda vicdanımın sesini dinlerim. & $4.42 \pm 1.12$ & 0.653 & 0.832 \\
\hline $\begin{array}{l}\text { Madde11-Sağlık bakım alanında çalışmayı sürdürmek için } \\
\text { vicdanımı köreltmek zorundayım. }\end{array}$ & $2.26 \pm 1.36$ & 0.124 & 0.858 \\
\hline Madde12-Vicdanım çok katı & $1.92 \pm 1.18$ & 0.090 & 0.857 \\
\hline Madde 9-Vicdanımızın sesi bizi yanlış yönlendirebilir. & $2.50 \pm 1.36$ & 0.148 & 0.856 \\
\hline Madde13- Vicdanımız sosyal değerlerimizi ifade eder. & $3.72 \pm 1.27$ & 0.523 & 0.837 \\
\hline $\begin{array}{l}\text { Madde 16- Yapmam gerekenleri yapamadığımda vicdanen } \\
\text { kendimi kötü hissediyorum. }\end{array}$ & $4.77 \pm 1.06$ & 0.551 & 0.837 \\
\hline
\end{tabular}

\subsubsection{Test-tekrar test (Zamana göre değişmezlik) güvenilirliği sonuçları}

Ölçeğin test-tekrar test puan ortalamaları arasındaki uyumluluk durumunu belirlemek amaciyla korelasyon analizi (Pearson Momentler Çarpımı Korelasyonu) yapıldı ve $\mathrm{r}=0,97$ tespit edildi.

Tablo 2. Vicdan Algısı Ölçeği Faktör Analizi $(n=$ 163)

\begin{tabular}{|l|c|c|}
\hline Maddeler & $\begin{array}{l}\text { Faktör I } \\
\text { (Duyarlılık) }\end{array}$ & $\begin{array}{l}\text { Faktör II } \\
\text { (Otorite) }\end{array}$ \\
\hline Madde 15 & 0.802 & \\
\hline Madde 8 & 0.786 & \\
\hline Madde 5 & 0.740 & \\
\hline Madde 1 & 0.737 & \\
\hline Madde 3 & 0.705 & \\
\hline Madde 7 & 0.700 & \\
\hline Madde 16 & 0.661 & \\
\hline Madde 2 & 0.647 & \\
\hline Madde 4 & 0.631 & \\
\hline Madde 13 & 0.593 & \\
\hline Madde 6 & 0.470 & \\
\hline Madde 14 & & 0.494 \\
\hline Madde 10 & & 0.689 \\
\hline
\end{tabular}

\subsubsection{Açıklayıcı Faktör Analizi}

Vicdan Algısı Ölçeği, orjinalindeki 6 faktörlü yapıyı doğrulayıcı faktör analizinde doğrulamadığı için açıklayıcı faktör analizi yapıldı. Ölçek maddelerinin faktör yükleri 0,47 ile 0,80 arasındadır. Faktör analizi sonucunda maddelerin toplam varyansın \% 52,5'ini açıklayan iki faktör altında toplandığı bulundu. Ölçeğin Cronbach Alpha değeri 0,84'dür. Faktör 1 (Duyarllılı)
(Maddeler 8, 15, 5, 1, 7, 3, 2, 4, 6, 13, 16) toplam 11 maddeden ve Faktör 2 (Otorite) (Maddeler 10, 14) toplam iki maddeden oluştu (Tablo 2). Açıklayıcı faktör analizi sonucunda ölçeğin Türkçe geçerlilik ve güvenilirliğinin, 13 maddeli ve iki faktörlü bir yapıdan oluştuğu görüldü.

\section{Tartışma}

"Vicdan Algısı Ölçeği" Dahlquist ve arkadaşları tarafından 2007 yılında İsveç'de geliştirilmiş ve hemşireler üzerinde geçerlilik güvenilirliği yapılmış bir ölçektir [5]. Ölçeğin orjinali, 15 maddeden ve 6 faktörden oluşmaktadır. Fakat Ahlin ve arkadaşlarının 1 madde daha eklemesiyle 2012 yilinda 16 madde ile yayınlanmıștır [6]. Ölçeğin Türkiye'de hemşirelerde kullanılabilmesi için yapmış olduğumuz geçerlilik ve güvenilirlik analizlerinde çıkan sonuçlar hemşirelerde kullanılabileceğini doğrular niteliktedir.

Araştırmada vicdan algısı ölçeğinin kapsam ve yapı geçerliliğini belirlemeye yönelik yapılan kapsam değerlendirmesinde; dil değerlendirmeleri yapıldıktan sonra ölçek soruları uzmanlara sunulmuş ve puanlamaları istenmiştir. Konu ile ilgili uzman kişilerin değerlendirmesinde ölçek maddeleri üzerinde CVI değeri bakımından \% 92 uzlaşma sağlanmıştır. CVI değeri \% 80'den büyük ise madde kapsam geçerliliği açısından yeterlidir [13]. Kendall W testinde ise gözlemci, uzman ya da hakemlerin gözledikleri verilerin değerleri arasındaki uyuma bakılır. $\mathrm{W}$ testinde 0 (uyum yok) ve 1 (tam uyum) olarak tanımlanır. Çıkan değerin 1'e yaklaşması gözlemci ya da hakemlerin birbiri 
arasındaki uyumun arttığının ve ortak görüş bildirdiklerinin göstergesidir $[14,15,16]$. Bu çalışmada uzmanlar, ölçek maddeleri konusunda görüş birliğine varmıştır.

Ölçeğin iç tutarlılık ve madde analizlerinde maddetoplam ölçek çözümlemesi ve Cronbach alpha güvenilirlik analizleri yapılmıştır. Güvenirlik analizleri kapsamında uygulanan güvenilirlik testinde Cronbach Alpha katsayısı 0,84'dür. Ahlin ve arkadaşlarının İsveç'de yaptığı çalışmada ise 0,70 bulmuşlardır [6]. Cronbach alfa katsayısı, ölçekte yer alan k maddenin varyansları toplamının genel varyansa oranlanması ile bulunan bir ağırlıklı standart değişim ortalamasıdır. Her bir madde için saptanan tek bir $\alpha$ değeri olabileceği gibi, ölçekteki tüm maddelere ait ortalama bir $\alpha$ değeri de olabilir. Tüm maddeler için elde edilen $\alpha$ değeri o ölçeğin toplam güvenilirliğini gösterir. Genel olarak kabul edilen değer 0,70 ve üzeridir. Çıkan katsayı değerinin 1'e yaklaşması ölçekte yer alan maddelerin iç tutarlılığının yüksek olduğunun kanıtıdır [17,18,19,20]. Güvenirlik katsayısının 0,70 ve daha yüksek olması test puanlarının güvenirliği için genel olarak yeterli görülmektedir [21,22]. Bu çerçevede incelendiğinde ölçeğin Türkçe'ye uyarlamasının da güvenilir olduğu söylenebilir.

Ölçeğin madde-toplam puan korelasyon katsayıları (r) $0,090-0,697$ arasında olduğu ve aralarındaki ilişkinin pozitif yönde istatistiksel yönden ileri düzeyde anlamlı olduğu $(p<0,001)$ saptanmıştır. Dahlquist ve ark çalışmasında $0,47-0,82$ arasında bulunmuştur [5]. Madde-toplam puan korelasyon katsayılarına göre bazı kaynaklar 0,50'den küçük katsayısı olan maddelerin güvenirliğinden kuşku duyulması gerektiği, bazı kaynaklarda ise bu katsayının 0,30'un üzerinde olması gerektiği belirtilmektedir [23]. Ancak çoğu araştırmacı 0,20 'nin sınır değer olarak alınması gerektiğini ifade etmişlerdir [16,24]. Bu sonuca göre Madde 9, Madde 11 ve Madde 12 madde- toplam korelasyonu 0,20'nin altında olduğu için ölçekten çıkarılmıştır. Ahlin ve arkadaşları çalışmasında da bu çalışmaya benzer sonuçlar çıkmış Madde11 ve Madde 12 ölçekten çıkarılmıştır [6].

Çalışmamızda ölçeğin zamana göre değişmezlik değerlendirmesi için, dört hafta ara ile yapılan testtekrar test değerlendirmesinde aralarındaki uyumu tespit etmek için Pearson Momentler Çarpımı Korelasyonu yapılmış olup $\mathrm{r}=0,97$ bulunmuştur. Test tekrar test yöntemi geçerlilik ve güvenilirlik analizlarinde en s1k kullanılan yöntemlerden biridir [25]. Bizim bulduğumuz değere göre bir ay arayla aynı gruba uygulanan ölçeğin puanlarının birbiriyle uyumlu olduğunu görülmektedir.

Vicdan Algısı ölçeği, orjinalindeki 6 faktörlü yapıyı doğrulayıcı faktör analizinde doğrulamadığı için sadece açıklayıcı faktör analizi yapılmıştır. Faktör analizi ölçülebilen ve görülebilen çok sayıdaki özelliğin arkasında yatan gerçek sebepleri, yani gözlenemeyen ve ölçülemeyen gizli boyutları ortaya çıkarmaya yarayan bir yöntemdir [26]. Bu çalışmada analiz, çıkarılan 3 maddenin dışında kalan 13 madde üzerinde yapılmıştır. Bu 13 maddenin faktör yükleri 0,47 ile 0,80 arasındadır. Bizim çalışmamızda faktör analizi sonuçlarına göre en düşük varyans değerimiz 0,47 olup Tabachnick ve Fidell'in önerdiği sınır olan 0,40'ın üzerindedir [27]. Ölçek bu haliyle Dahlquist ve ark çalışmasındaki madde yükleriyle de uyumludur [5]. Faktör analizi sonucunda maddelerin toplam varyansın \% 52.5'ini açıklayan iki faktör altında toplandığı bulunmuştur. Analizler sonucunda, Faktör 1 (Duyarlılık), Faktör 2 (Otorite) olmak üzere toplam iki faktör bulunmaktadır. Dahlquist ve ark çalışmalarında ölçek; Otorite (Auhority), Uyarı işaretleri (Warning Signal), Adanmış duyarlılık (Demanding Sensitivity), Değer (Asset), Yük (Burden), Kültüre bağlı (Depending Culture) başlıkları altında altı alt ölçekten oluşmuştur [5]. Vicdan Algısı Türkçe geçerlilik güvenilirliğini yapılan bu çalışmada ise açıklayıcı faktör analizi sonucunda ölçek, 13 maddeli ve iki faktörlü bir yapıdan oluşmaktadır.

\section{Sonuç ve öneriler}

Yapılan istatistiksel analizler sonucunda "Vicdan Algisı Ölçeği” Türkiye'de hemşirelerin vicdan algısını belirlemek için yapılan çalışmalarda 13 maddeli haliyle kullanılabilir. Ölçeğin diğer sağlık bakım vericileri ve hastalarla bakımına etkin katılan sağlık çalışanları ile de test edilmesi uygun olabilir.

\section{Kaynaklar}

1. Ferguson, S, Wright, D, Packer, J, New Dictionary of Theology; Leicester: Inter Varsity Press, 1988.

2. Conscience, Oxford Dictionary; [2019.03.25] https://en.oxforddictionaries.com/definition/conscience.

3. Lamb, C, Evans, M, Babenko-Mould, Y, Wong, C.A, Kirkwood, K.W, Conscience, conscientious objection, and nursing: A concept analysis, Nurs Ethics, 2019 Feb, 26(1), 37-49. Doi: 10.1177/0969733017700236.

4. Ramsey, H, Conscience: Aquinas - with a hint of aristotle, Sophia, 2001 December; 40(2): 15-29.

5. Dahlqvist, V, Eriksson, S, Glasberg, A.L, Lindahl, E, Lützén, K, Strandberg, G, Söderberg, A, Sørlie, V, Norberg, A, Development of the perceptions of conscience questionnaire, Nurs Ethics, 2007, 14(2), 181-93. Doi: 10.1177/0969733007073700.

6. Ahlin, J, Ericson-Liedman, E, Norberg, A, Strandberg, G, Revalidation of the Perceptions of Conscience Questionnaire (PCQ) and the Stress of Conscience Questionnaire (SCQ), Nurs Ethics, 2012, 19(2), 220-32. Doi: 10.1177/0969733011419241.

7. Torjuul, K, Nordam, A, Sorlie, V, Action ethical dilemmas in surgery: an interview study of practicing surgeons, $B M C$ Med Ethics, 2005 Jul 4, 6(7), 1-9. Doi: 10.1186/14726939-6-7.

8. Lützén, K, Dahlqvist, V, Eriksson, S, Norberg, A, Developing the concept of moral sensitivity in health care practice, Nurs Ethics, 2006 Mar; 13(2): 187-96. Doi: 10.1191/0969733006ne837oa.

9. Cleary, M, Lees, D, The role of conscience in nursing practice, Issues Ment Health Nurs, 2019 Mar, 40(3), 281283. Doi: 10.1080/01612840.

10. Glasberg, A.L, Eriksson, S, Dahlqvist, V, Lindahl, E, Strandberg, G, Söderberg, A, Sørlie, V, Norberg, A, Development and initial validation of the stress of conscience questionnaire, Nursing Ethics, 2006, 13(6), 633-48. Doi: 10.1177/0969733006069698. 
11. Mazaheri, M, Ericson-Lidman, E, Joakim, O, Norberg, A, Meanings of troubled conscience and how to deal with it: expressions of Persian-speaking enrolled nurses in Sweden, Scand J Caring Sci, 2018 Mar, 32(1), 380388. Doi: $10.1111 / \mathrm{scs} .12472$.

12. Plictha, S.B, Kelvin, E, Munro's statistical methods for health care research; Sixth Edition. Wolters Kluwer Health / Lippincott Williams \& Wilkins, 2013.

13. Rutherford-Hemming, T, Determining content validity and reporting a content validity index for simulation scenarios, Nursing Education Perspectives, 2015, 36(6), 389-393. Doi: 10.5480/15-1640.

14. SPSS - Kendall's Concordance Coefficient W; [2019.06.19] https://www.spss-tutorials.com/spsskendalls-concordance-coefficient-w/.

15. Karagoz, Y, The power and effectiveness of nonparametric techniques, Electronic Journal of Social Sciences, 2010, 9(33), 18-40.

16. Aksoy, S.D, Dutucu, N, Özdilek, R, Bektaş, H.A, Keçeci, A, Gebelik stresi değerlendirme ölçeği'nin Türkçe'ye uyarlanması, Kocaeli Üniversitesi Sağllk Bilimleri Dergisi, 2019, 5(1), 11-15. Doi:10.30934/kusbed.467716.

17. Cronbach, L.J, Coefficient alpha and the internal structure of tests, Psychometrika, 1951, 16(3), 297-334. Doi: 10.1007/BF02310555.

18. Sijtsma, K, On theuse, the misuse, and the very limited usefulness of cronbach's alpha, Psychometrika, 2009 74(1), 107-120. Doi: 10.1007/s11336-008-9101-0.

19. Kılıç, S, Cronbach'ın alfa güvenirlik katsayısı, Journal of Mood Disorders, 2016, 6(1), $47 . \quad$ Doi: 10.5455/jmood.20160307122823.

20. Kula Kartal, S, Mor Dirlik, E, Historical development of the concept of validity and the most preferred technique of reliability: cronbach alpha coefficient, Abant Izzet Baysal Üniversitesi Eğitim Fakültesi Dergisi, 2016, 16(4), 1865-1879.

21. Tavşancıl, E, Tutumların ölçülmesi ve SPSS ile veri analizi; 2.baskı. İstanbul: Nobel Yayın Dağıtım, 2005.

22. Field, A, Discovering statistics using IBM SPSS Statistics; SAGE Publications Ltd, 2013.

23. Karaman, H, Atar, B, Çobanoğlu Aktan, D, Açımlayıcı Faktör Analizinde Kullanılan Faktör Çıkartma Yöntemlerinin Karşılaştırılması, GEFAD / GUJGEF, 2017, 37(3), 1173-1193.

24. Büyüköztürk, Ș, Sosyal Bilimler İçin Veri Analizi El Kitabı; Üçüncü baskı, Ankara, Pegem A Yayıncılık, 2003.

25. DeVon, H.A, Block, M.E, Moyle-Wright, P, Ernst, D.M, Hayden, S.J, Lazzara, D.J, Savoy, S.M, Kostas-Polston, E, A psychometric toolbox for testing validity and reliability, Journal of Nursing Scholarship, 2007, 39(2), 155-164. Doi: 10.1111/j.1547-5069.2007.00161.x

26. Yaşlığlu, M.M, Factor analysis and validity in social sciences: application of exploratory and confirmatory factor analyses, Istanbul University Journal of the School of Business, 2017, 46, 74-85.

27. Tabachnick, B.G, Fidell, L.S, Using multivariate statistics; 4th edition. Allyn and Bacon, 2001.

http://edergi.cbu.edu.tr/ojs/index.php/cbusbed isimli yazarın CBU-SBED başlıklı eseri bu Creative Commons Alınt1-Gayriticari4.0 Uluslararası Lisansı ile lisanslanmıştır. 